\title{
Dynamic Analysis of High Rise Seismically Isolated Buildings
}

\author{
Mohammed Naguib, Fikry A. Salem, Khloud El-Bayoumi
}

Civil Engineering Dep., Faculty of Engineering, Mansoura University, Egypt

Email address:

engkhloud@yahoo.com (K. El-Bayoumi)

To cite this article:

Mohammed Naguib, Fikry A. Salem, Khloud El-Bayoumi. Dynamic Analysis of High Rise Seismically Isolated Buildings. American Journal of Civil Engineering. Vol. 3, No. 2, 2015, pp. 43-50. doi: 10.11648/j.ajce.20150302.13

\begin{abstract}
The purpose of this paper is to offer a relative understanding of the seismic performance enhancements that a typical 40-story steel office building can achieve through the implementation of base isolation technology. To reach this understanding, the structures of a fixed-base office building and a base-isolated office building of similar size and layout were designed; their seismic performance was compared in both response spectrum analysis and time history analysis. As a result of this paper, building owners and construction industry professionals can recognize the benefits of implementing base isolation on a wider range of projects, thereby creating the potential for a significant increase in the technology's use.
\end{abstract}

Keywords: Triple Friction Pendulum Bearing, Structure Control, Seismic Isolation, Base Isolation, High Rise Buildings

\section{Introduction}

A critical aspect in the design of civil engineering structures is the reduction of response quantities such as velocities, deflections and forces induced by environmental dynamic loadings (i.e., wind and earthquake). Structural control methods are the most recent strategies for this purpose, which can be classified as active, semi-active, passive, and hybrid control methods [1]. Control methods have been slow in their acceptance in the structural design community because the systems are often prohibitively complicated, large and expensive. Over time, however, their utility is becoming more recognized and improvements in the technology are making them more viable options in new construction and retrofits.

In the last three decades or so, the reduction of structural response, caused by dynamic effects, has become a subject of research, and many structural control concepts have been implemented in practice [2].

Base isolation systems are one of the most successful and widely-applied methods of mitigating structural vibration and damage during seismic events. Base isolation systems have been installed in numerous full-scale structures [3]. Sliding isolator works on principle of friction. This approach is based on the premise that the lower the friction coefficient, the less the shear transmitted [4]. The type of base isolation technology that is used in this study is the Triple Friction Pendulum (TFP) bearing. The Triple Friction Pendulum (TFP) bearing differs from the single Friction Pendulum (FP) bearing in that there are 3 friction pendulum mechanisms existing in each bearing instead of just 1 mechanism. These mechanisms are activated at different stages as the seismic demand gets stronger. The 3 mechanisms are achieved by using 4 concave surfaces in a single bearing, with sliding occurring on two of the surfaces at a given time [5].An image of the TFP's disassembled parts and a cross section of a TFP bearing are shown in Figures A, B below, respectively [6], [7].

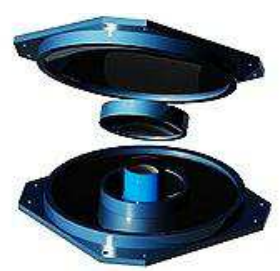

(a)
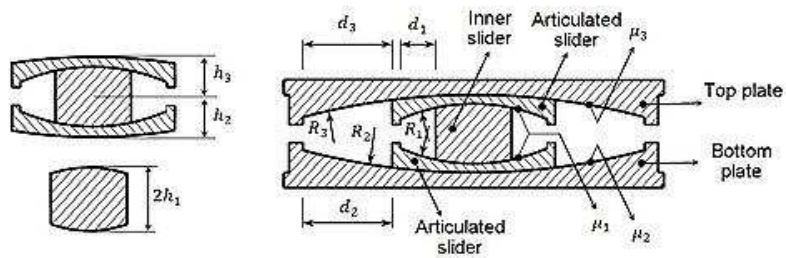

(b)

Figure A. Triple friction pendulum bearing, (a) Three-dimensional view; (b) Section view and basic parameters. 


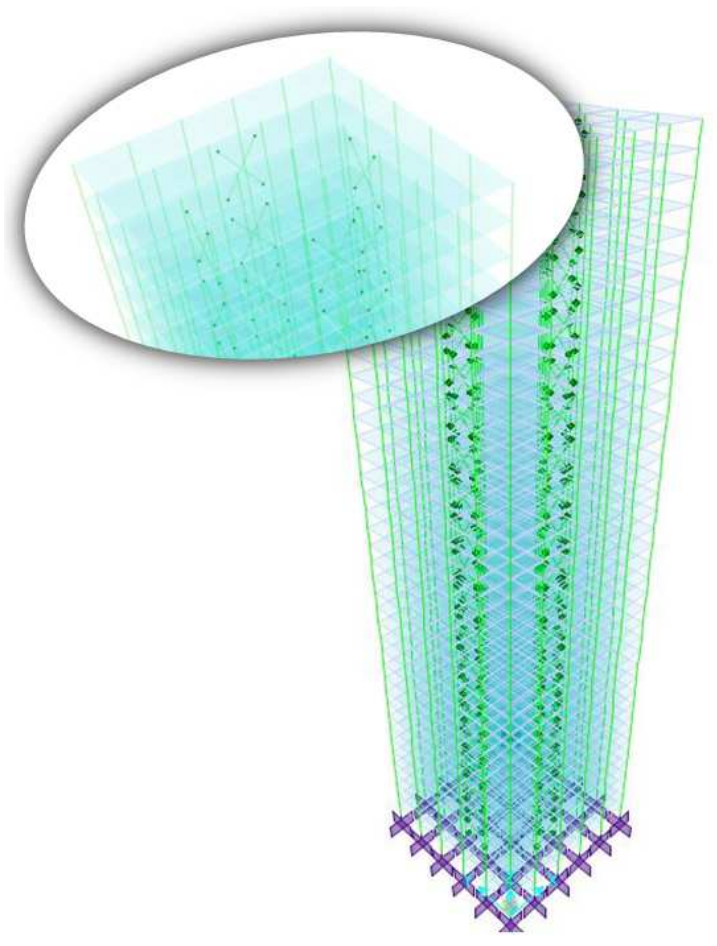

Figure B. $3 D$ view of the SAP2000 model.

\section{Structural Model}

A model of $(30 * 30) \mathrm{m} 40$-story building was created with steel columns, beams and sections of $0.2 \mathrm{~m}$ width concrete slab. The steel superstructure had a lateral system of special concentrically braced frames (SCBF) in both the transverse and longitudinal directions, and that structural system was used for both of the fixed-base and isolated-base buildings designed for this study. Building place was assumed to be in Cairo and according to USGS worldwide seismic design tool [8] it was found that response spectrum parameters were $0.5815 \mathrm{~g}$ and $0.3395 \mathrm{~g}$ for $\mathrm{S}_{\mathrm{DS}}$ and $\mathrm{S}_{\mathrm{D} 1}$ respectively, $0.509 \mathrm{~g}$ and $0.872 \mathrm{~g}$ for $\mathrm{S}_{\mathrm{M} 1}$ and $\mathrm{S}_{\mathrm{MS}}$ respectively.

\section{TFP Bearings}

To create the isolated-base model, three TFP bearings were assumed with the following properties:

\subsection{Calculating $D_{D}$ (Upper Bound Analysis)}

Table A. basic parameters for calculating $D_{D}$

\begin{tabular}{llllllll}
\hline & $\boldsymbol{\mu}$ & $\boldsymbol{\mu}_{\mathbf{1}}$ & $\mathbf{D}_{\mathbf{y}}$ & $\mathbf{F}_{\mathbf{d} \mathbf{1}}$ & $\mathbf{W}$ & \#B & $\boldsymbol{\Sigma} \mathbf{W}$ \\
\hline TFP1 & 0.082 & 0.085 & 0.00693 & 0.37711 & 324 & 4 & 1296 \\
TFP2 & 0.092 & 0.094 & 0.00789 & 0.277243 & 648 & 16 & 10368 \\
TFP3 & 0.112 & 0.112 & 0.00107 & 0.202702 & 1296 & 16 & 20736 \\
& & & $\Sigma$ & 7566.413 & & & 32400 \\
\hline
\end{tabular}

1) Let the displacement be $D_{D}=0.63$

2) Effective stiffness: $Q_{d}=\mu . \Sigma W=3382.6$

$$
\begin{gathered}
\mathrm{K}_{\mathrm{D}}=\Sigma \mathrm{F}_{\mathrm{D}} / \mathrm{D}_{\mathrm{D}}=12010 \\
\mathrm{~K}_{\mathrm{eff}}=\mathrm{K}_{\mathrm{D}+\mathrm{Q}_{\mathrm{d}} / \mathrm{D}_{\mathrm{D}}=17379}
\end{gathered}
$$

3) Effective period: (Eq.17.5-2, ASCE 7-10) [9]

$$
T_{e f f}=2 \pi \sqrt{\frac{\Sigma W}{K_{e f f} \cdot g}}=2.7402
$$

4) Effective damping: (Eq.17.8-7, ASCE 7-10) [9]

$$
\beta_{D}=\frac{E}{2 \pi K_{e f f} D_{D}^{2}}=\frac{4 \mu \Sigma\left(D_{D}-D_{y}\right)}{2 \pi K_{e f f} D_{D}^{2}}=0.1956
$$

5) Damping reduction factor:

$$
\beta=\left(\frac{\beta_{\text {eff }}}{0.05}\right)^{0.3}=1.5056
$$

6) Check $D_{D}^{\prime}$ :

$$
D_{D}^{\prime}=\frac{S_{D 1} \cdot T_{e f f}^{2}}{4 \pi^{2} \cdot \beta} g=0.6302
$$

Table B. Summary of Isolation Bearing Properties.

\begin{tabular}{llll}
\hline Property & TFP1 & TFP2 & TFP3 \\
\hline Place & Corner columns & $\begin{array}{l}\text { Outer } \\
\text { columns }\end{array}$ & $\begin{array}{l}\text { Inner } \\
\text { columns }\end{array}$ \\
Vertical load ton & 324 & 648 & 1296 \\
$\mathrm{R}_{\text {leff }}=\mathrm{R}_{4 \mathrm{eff}} \mathrm{mm}$ & 2133 & 3395 & 6934 \\
$\mathrm{R}_{2 \mathrm{eff}}=\mathrm{R}_{3 \text { eff }} \mathrm{mm}$ & 330 & 526 & 1074 \\
$\mathrm{~d}_{1}{ }^{*}=\mathrm{d}_{4}{ }^{*}$ mm & 339.8 & 540.4 & 1103.48 \\
$\mathrm{~d}_{2}{ }^{*}=\mathrm{d}_{3}{ }^{*}$ mm & 41.5 & 65.9 & 30.85 \\
$\mu_{1}=\mu_{4}$ Lower bound & 0.071 & 0.078 & 0.093 \\
$\mu_{2}=\mu_{3}$ Lower bound & 0.053 & 0.066 & 0.093 \\
$\mu$ Lower bound & 0.068 & 0.076 & 0.093 \\
$\mu_{1}=\mu_{4}$ Upper bound & 0.085 & 0.094 & 0.112 \\
$\mu_{2}=\mu_{3}$ Upper bound & 0.064 & 0.079 & 0.111 \\
$\mu$ Upper r bound & 0.082 & 0.092 & 0.112 \\
\hline
\end{tabular}

\subsection{Sap2000 Link/Support Property Data Input (Upper Bound)}

SAP 2000 version 16.0 and later versions has a direct link property that simulates the actual behavior of triple friction pendulum bearing [10], and then the 3 bearings input data are shown in figures below: 


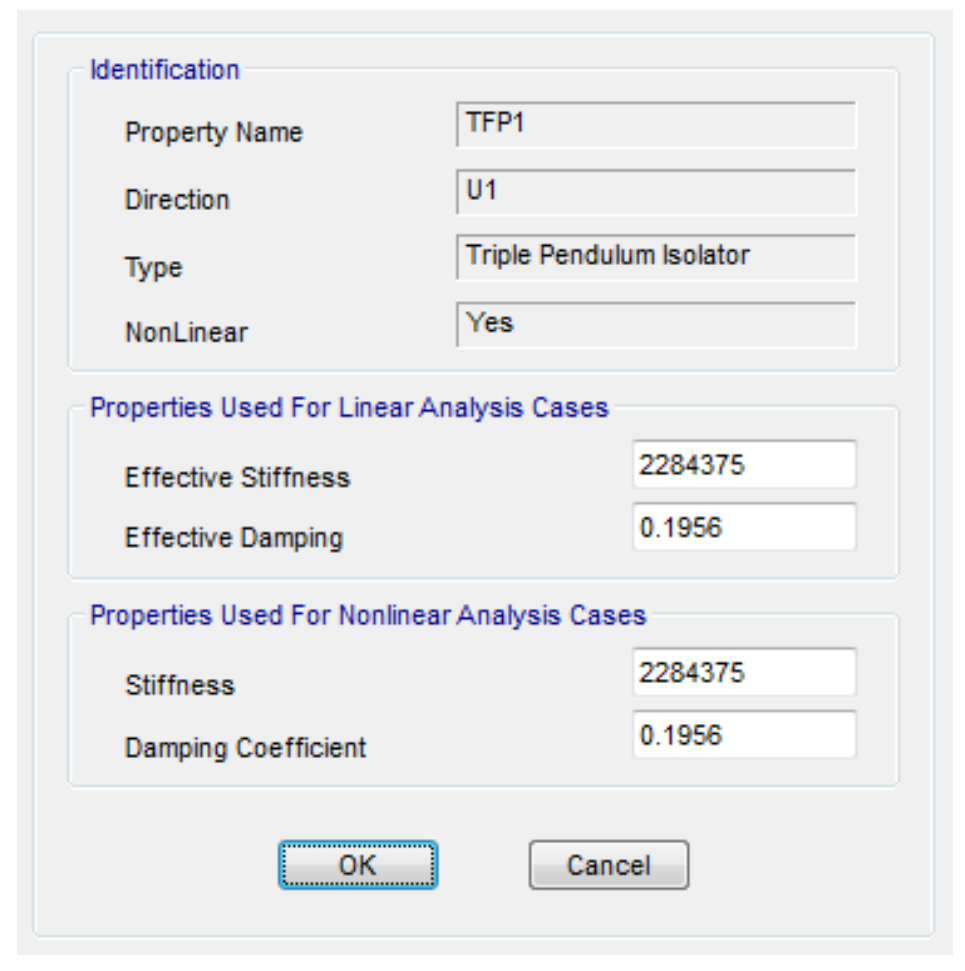

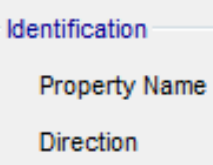

$\frac{\text { TFP1 }}{\text { U2; U3 }}$

U2; U3

Type
NonLinear

Effective Stiffness - U3

Effective Damping - U3

\begin{tabular}{|l|}
\hline 194.07 \\
\hline 0.1956 \\
\hline
\end{tabular}

\section{Shear Deformation Location}

Distance from End-J - U2

0.

Distance from End-J - U3

0 .

Height and Symmetry of Sliding Surfaces
Height for Outer Surface
0.102
$\checkmark$ Outer Bottom Surface is Symmetric to Outer Top Surface
Height for Inner Surface
0.076
[V Inner Bottom Surface is Symmetric to Inner Top Surface

Nonlinear Properties for Directions U2 and U3

\begin{tabular}{|c|c|c|c|c|}
\hline & Outer Top & Outer Bottom & Inner Top & Inner Bottom \\
\hline Stiffness & 3974.026 & 3974.026 & 2992.21 & 2992.21 \\
\hline Friction Coefficient, Slow & 0.085 & 0.085 & 0.064 & 0.064 \\
\hline Friction Coefficient, Fast & 0.17 & 0.17 & 0.128 & 0.128 \\
\hline Rate Parameter & 0.5 & 0.5 & 0.5 & 0.5 \\
\hline Radius of Sliding Surface & 2.133 & 2.133 & 0.33 & 0.33 \\
\hline Stop Distance & 0.69346 & 0.69346 & 0.01386 & 0.01386 \\
\hline
\end{tabular}

OK

Figure C. SAP2000 Friction Pendulum Bearing Properties for TFP1, a. Vertical direction U1; b. Lateral direction U2, U3. 


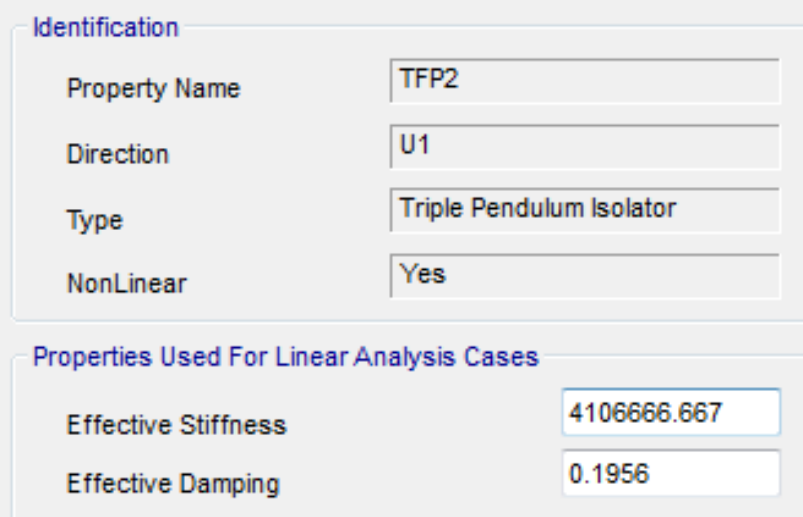

Properties Used For Nonlinear Analysis Cases

Stiffness

4106666.667

Damping Coefficient

0.1956

\section{Identification

Property Name \\ Direction}

$\frac{\sqrt{\text { TFP2 }}}{\text { U2; U3 }}$

\section{Linear Properties}

Effective Stiffness - U2

Effective Damping - U2

\begin{tabular}{|l|}
\hline 285.4975 \\
\hline 0.1956
\end{tabular}

\section{Type}

NonLinear
Triple Pendulum

Yes

Shear Deformation Location

Distance from End-J - U2

0.

Distance from End-J - U3

\begin{tabular}{|l|}
\hline 285.4975 \\
\hline 0.1956
\end{tabular}

Effective Damping - U3

Height and Symmetry of Sliding Surfaces

Height for Outer Surface

0.161

$\checkmark$ Outer Bottom Surface is Symmetric to Outer Top Surface

Height for Inner Surface

0.121

$\checkmark$ Inner Bottom Surface is Symmetric to Inner Top Surface

Nonlinear Properties for Directions U2 and U3

\begin{tabular}{|c|c|c|c|c|}
\hline & Outer Top & Outer Bottom & Inner Top & Inner Bottom \\
\hline Stiffness & 7720.152 & 7720.152 & 6488.213 & 6488.213 \\
\hline Friction Coefficient, Slow & 0.094 & 0.094 & 0.079 & 0.079 \\
\hline Friction Coefficient, Fast & 0.188 & 0.188 & 0.158 & 0.158 \\
\hline Rate Parameter & 0.5 & 0.5 & 0.5 & 0.5 \\
\hline Radius of Sliding Surface & 3.395 & 3.395 & 0.526 & 0.526 \\
\hline Stop Distance & 1.09658 & 1.09658 & 0.01578 & 0.01578 \\
\hline
\end{tabular}

Figure D. SAP2000 Friction Pendulum Bearing Properties for TFP2, a. Vertical direction U1; b. Lateral direction U2, U3. 


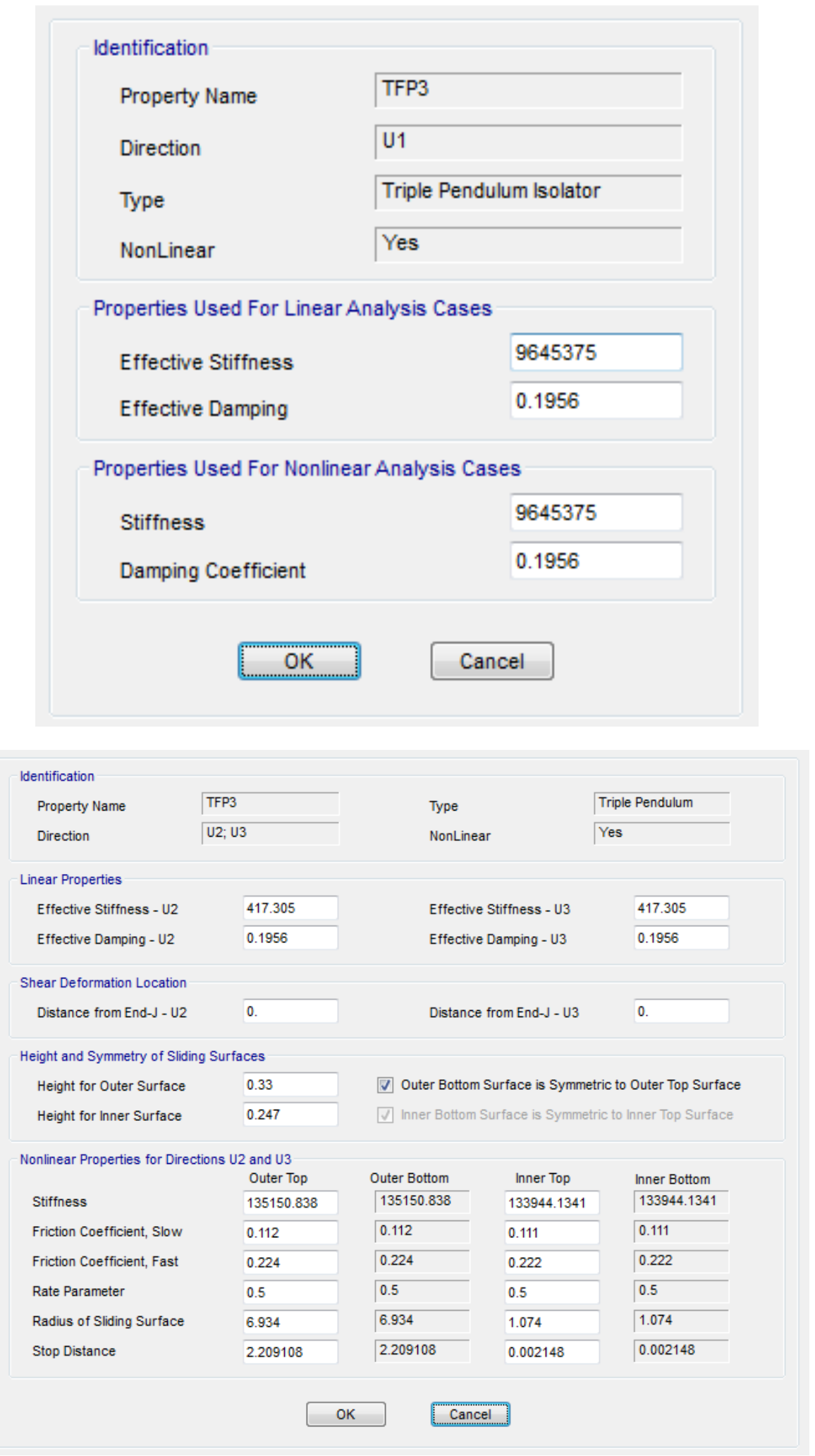

Figure E. SAP2000 Friction Pendulum Bearing Properties for TFP3, a. Vertical direction U1; Lateral direction U2, U3.

\section{Time History Data Input}

In order to account for the variation of the building's response throughout the duration of each earthquake ground motion, a time history analysis was required. Ground motions representative of different hazard levels have been assembled for this research. All these ground motions are assembled from The Pacific Earthquake Engineering Research Center ground motion database [11]. 
Table C. Time history EQ Ground Motions.

\begin{tabular}{lllll}
\hline NGA\# & EQ Name & Year & Station & Magnitude \\
\hline 182 & "Imperial Valley-06" & 1979 & "El Centro Array \#7" & 6.53 \\
183 & "Imperial Valley-06" & 1979 & "El Centro Array \#8" & 6.53 \\
1605 & "Duzce Turkey" & 1999 & "Duzce" & 7.14 \\
1158 & "Kocaeli Turkey" & 1999 & "Duzce" & 7.51 \\
\hline
\end{tabular}

\section{Analysis}

\subsection{Modal Analysis}

The figure $G$ below illustrates the modal periods resulted from the response spectrum modal analysis. And it was found that the average modal period increased by about $9.11 \%$.

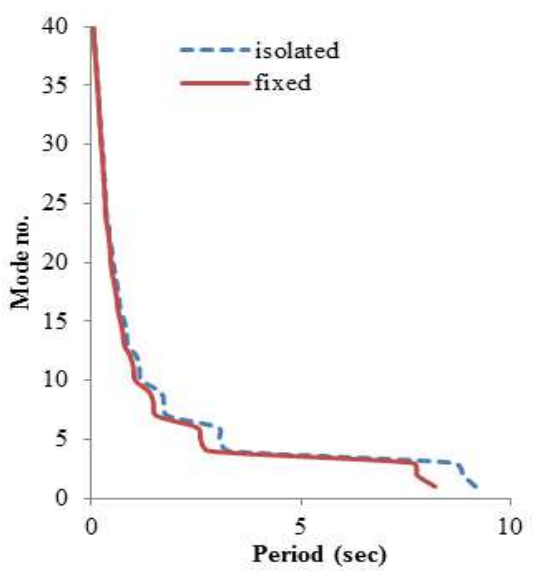

Figure F. Modal periods for fixed and isolated models.

\subsection{In-Story Drift}

For the response spectrum analysis, the design drift for the fixed-base was and isolated-base models were 0.00637, 0.00246 respectively, which met the design drift limit of 0.0150 For the time history analysis; the design drifts of motion 182 were $0.016123,0.000855$ for fixed and isolated models, for motion 183 they were $0.016095,0.000668$ for motion 1158 they were $0.025387,0.000216$ and for motion 1605 they were $0.028296,0.001506$.

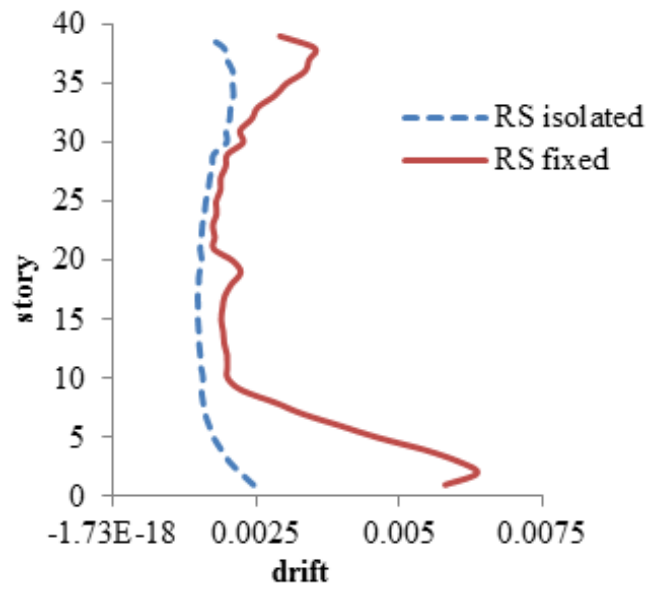

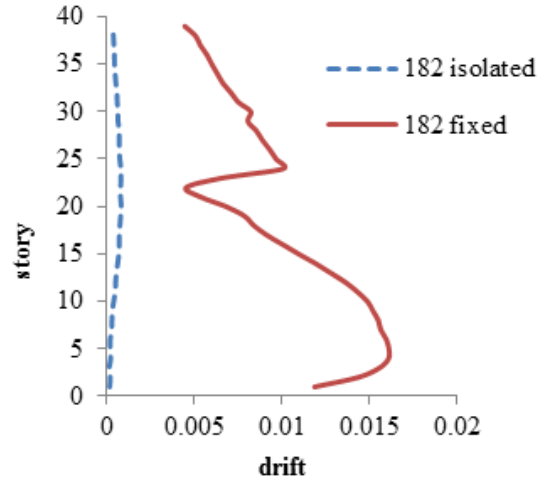
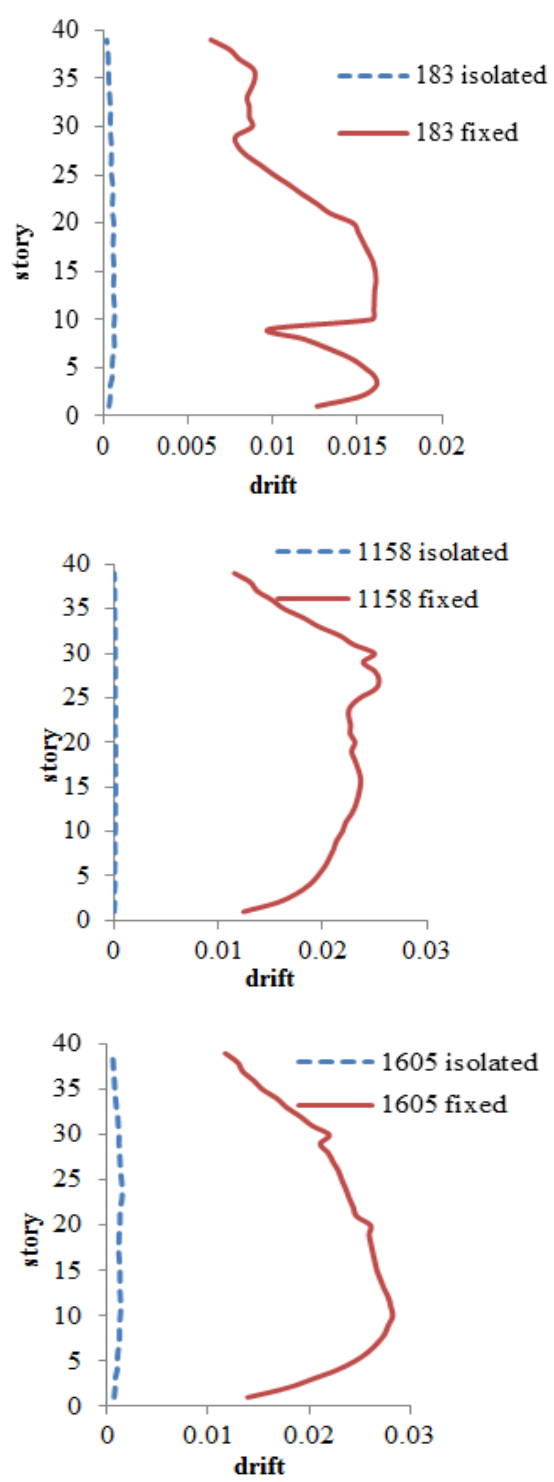

Figure G. In story drift due to response spectrum and time history analysis. 
It was foundthat the in-story drift for the isolated model was $29.61 \%$ less than the fixed model in case of response spectrum analysis and $93.23 \%, 95.63 \%, 99.25 \%, 95.09 \%$ in time history analysis motions $182,183,1158$, and 1605 respectively

\subsection{Floor Acceleration}

In case of response spectrum analysis; the resulted maximum story acceleration was $0.337 \mathrm{~g}$ for fixed model and $0.0612 \mathrm{~g}$ for isolated model. In case of time history analysis it were $0.583 \mathrm{~g}, 0.889 \mathrm{~g}, 0.519 \mathrm{~g}$ and $0.669 \mathrm{~g}$ for fixed model and $0.341 \mathrm{~g}, 0.614 \mathrm{~g}, 0.312 \mathrm{~g}$ and $0.405 \mathrm{~g}$ for isolated model in motions $182,183,1158$ and 1605 respectively.

It was found that story acceleration for the fixed model was $72.87 \%$ higher than the isolated model in case of response spectrum analysis and $16.56 \%, 15.69 \%, 22.81 \%$ and $24.71 \%$ in time history analysis motions 182, 183, 1158, and 1605 respectively, Then it was noted that isolator system efficiency in decreasing story acceleration was directly proportional to motion intensity and reversely proportional to motion ground acceleration.
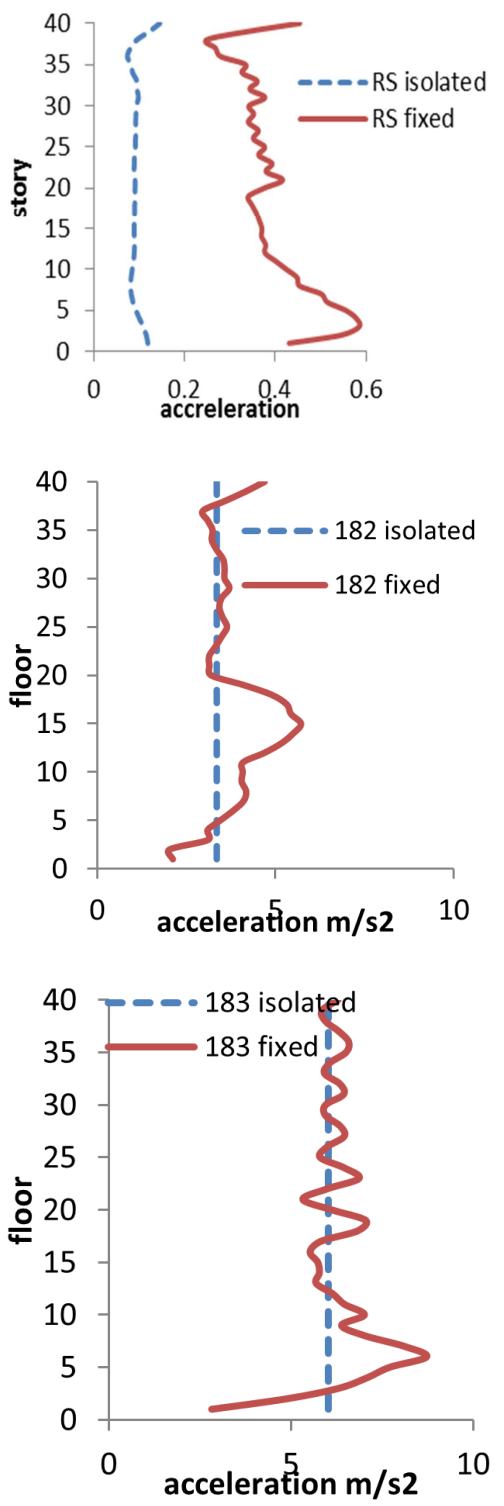
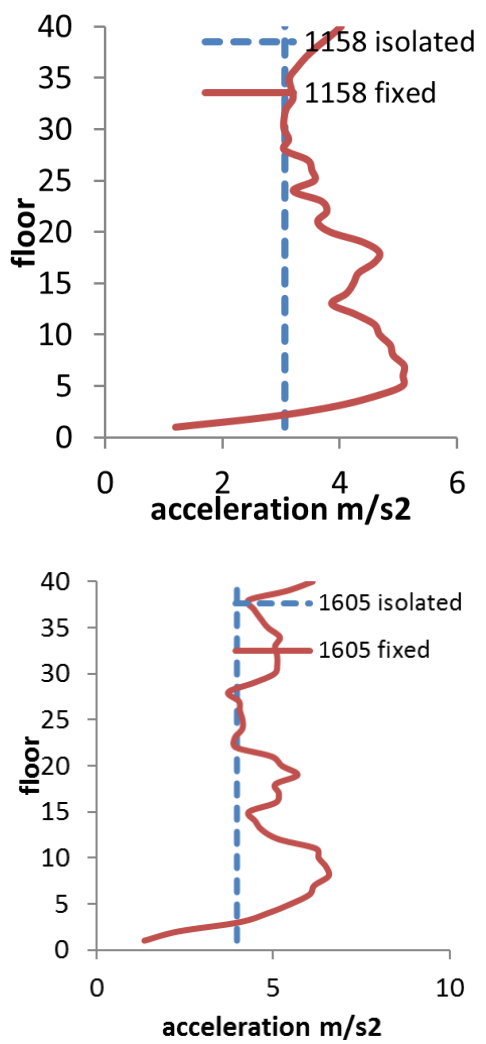

Figure $\boldsymbol{H}$. Floor acceleration due to response spectrum and time history analysis.

\subsection{Story Displacement}

In case of response spectrum analysis; the resulted maximum story displacement was $0.333 \mathrm{~m}$ for fixed model and $0.287 \mathrm{~m}$ for isolated model. In case of time history analysis it were $1.19,1.44,2.44$ and 2.64 for fixed model and $0.43,0.51,0.32$ and 0.69 for isolated model in motions $182,183,1158$ and 1605 respectively. Figure H illustrates the story displacements resulted from the response spectrum and time history analysis. And it was found that maximum story displacement for the isolated model was $13.79 \%$ less than the fixed model in case of response spectrum analysis and $63.92 \%, 64.41 \%, 87.08 \%, 74.1 \%$ in time history analysis motions $182,183,1158$, and 1605 respectively.

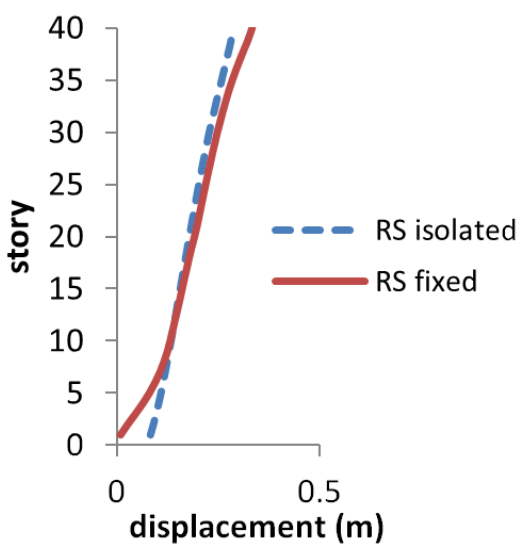



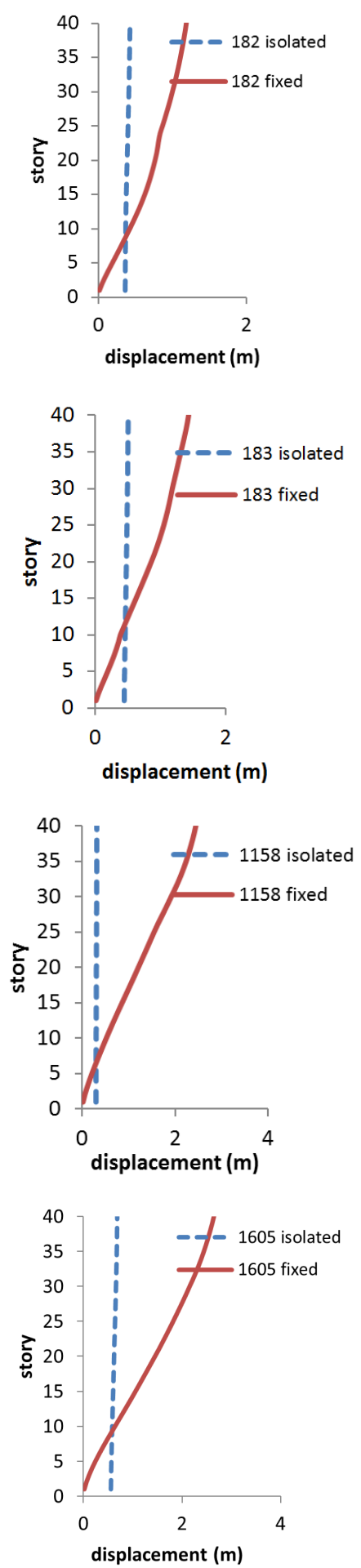

Figure H. Floor displacements due to response spectrum and time history analysis.

\section{Conclusion}

The benefits of implementing base isolation in the 40-story steel office building were clearly shown by the results of this study, including:

- Reduction of floor accelerations, in-story drifts and base reactions by more than $90 \%$ percentage.

- Improvement of structural seismic performance levels.
- Lowering the coefficients of friction of the TFP bearings is the most effective way to improve seismic performance (i.e. reduce the superstructure's response values, including floor accelerations and in-story drifts) when implementing base isolation in a tall, flexible building.

- Using TFP bearings with larger radii of curvature (R) leads to a more flexible (smaller lateral stiffness) isolation system and improves seismic performance, although larger bearing sizes are also more expensive.

- Isolator system efficiency in decreasing story displacement, in-story drift, story acceleration and base reactions was directly proportional to earthquake magnitude; and if two EQ have the same magnitude, then efficiency of isolator was reversely proportional to motion acceleration.

- Isolator system efficiency in decreasing base reactions was higher than its efficiency in decreasing in-story drift, story acceleration.

\section{References}

[1] T.K. Datta, Control of dynamic response of structures. Proc. of The Indo-US Symposium on Emerging Trends in Vibration and Noise Engineering, 1996, pp.18-20.

[2] R. Randa, T.T. Soong, Parametric study and simplified design of mass dampers. Engineering Structures, Vol. 20, No. 3, 1998, pp. $193-204$.

[3] Kelly J.M. Aseismic Base Isolation: Its History and Prospects. Proc. 1st World Congress on Joints and Bearings,1981, ACI-SP70, 1: 549-586.

[4] Mostaghel N. and Tanbakuchi J., Response of Sliding Structures to Earthquake Support Motion, Earthquake Engineering and Structural Dynamics, 11, 1983, 729-748

[5] Nicholas R. Marrs (2013). Seismic performance comparison of a fixed-base versus a base isolated office building.

[6] Dao ND, Ryan KL, Verification of a Three-dimensional Triple Pendulum Bearing Element with General Friction Model Using Full Scale Test Data. Submitted toEarthquake Engineering and Structural Dynamics, 2012.

[7] Dao ND. Experimental and Analytical Studies of the Seismic Response of a Full-scale 5-story Steel Moment Frame Building Isolated by Triple Pendulum Bearings.Dissertation,University of Nevada - Reno, 2012

[8] U.S. Geological Survey Earthquake Hazards Program: Seismic Hazard Maps and Data. (2012). http://geohazards.usgs.gov/designmaps/ww/.

[9] American Society of Civil Engineers - Code 7: Minimum Design Loads for Buildings and Other Structures. (2010). 21 June 2011.

[10] Khloud El-Bayoumi, Modeling of triple friction pendulum bearings in sap2000. International Journal of Advances in Engineering \& Technology, 2015, Vol. 8 issue 1.

[11] Pacific Earthquake Engineering Research Center (PEER). WebBased PEER Ground Motion Database (Beta Version) [Interactive web-site database]. Berkeley, California (2010). http://peer.berkeley.edu/peer_ground_motion_database. 